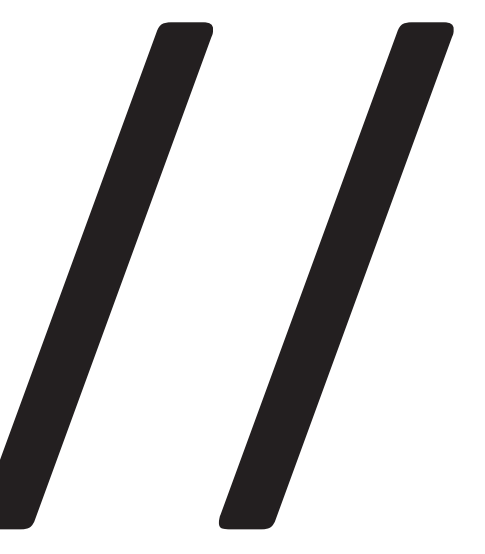

\title{
Cinema hipermaterialista: Bergson, Deleuze e a virtualização da matéria nos filmes de Louis Lumière
} Hyper-materialistic cinema: Bergson, Deleuze and the virtualization of matter in Louis Lumière's films

Marcelo Carvalho ${ }^{1}$ 
Dossiê A pesquisa em cultura audiovisual: novos desafios e aportes teóricos Cinema hipermaterialista: Bergson, Deleuze e a virtualização da matéria nos filmes de Louis Lumière

| Marcelo Carvalho

Resumo: o objetivo deste artigo é promover uma leitura materialista de algumas das primeiras obras de Louis Lumière, considerando o caráter transicional destes filmes entre a matéria e o cinema. Recorreremos a dois autores que não costumam embasar estudos sobre os primeiros filmes do cinema: Henri Bergson, autor de Matéria e memória, cujo primeiro capítulo retomaremos explícita ou implicitamente durante todo o percurso, e Gilles Deleuze, do qual tomaremos alguns conceitos oriundos dos livros A imagem-movimento e A imagem-tempo. Acreditamos ter encontrado no estatuto de "imagem-perceptual" a inclinação materialista das imagens de Lumière, nas quais identificamos a extensão do universo material enquanto virtualização da matéria.

Palavras-chave: Louis Lumière; Gilles Deleuze; Henri Bergson; matéria; imagem-perceptual.

Abstract: this paper aims to promote a materialistic review of some of the first Louis Lumière's works, considering the transitional character of these films between matter and cinema. It focuses on two authors who do not usually ground the studies on the earliest years of cinema. Henri Bergson, mainly, but not only, for the materialistic propositions addressed in the first chapter of Matter and memory, and Gilles Deleuze, from whom we take a few concepts covered in The movement-image and The timeimage. The perceptual-image status would rely on such materialistic inclination of Lumière's images, in which we identify an extension of material universe as matter virtualization.

Key words: Louis Lumière; Gilles Deleuze; Henri Bergson; matter; perceptual-image. 
Dossiê $A$ pesquisa em cultura audiovisual: novos desafios e aportes teóricos

Cinema hipermaterialista: Bergson, Deleuze e a virtualização da matéria nos filmes de Louis Lumière

| Marcelo Carvalho

\section{Introdução}

As imagens do início do cinema² foram alvo de inúmeras abordagens teóricas e históricas. Tais filmes, que formam um conjunto bastante heterogêneo, foram avaliados pela linha majoritária da historiografia tradicional "como propostas hesitantes, primitivas e desarticuladas" (COSTA, 2005, p. 72), julgados segundo critérios (como o de narração) que tinham o cinema institucional pós-Griffith como parâmetro $^{3}$. Mas no fim dos anos 1970 surgem novos estudos ${ }^{4}$ que advogam uma mudança de postura com relação ao período. Estas pesquisas passaram a levar mais em conta o panorama sociocultural do final do século XIX, notadamente a proximidade dos filmes (e do modo como eram exibidos) com os divertimentos populares da época e com o desenvolvimento em paralelo dos instrumentos óticos e dos espetáculos visuais, como os panoramas e os dioramas, além do interesse pela recepção e tipificação do público, pelos modos de produção empregados, pela organização econômica da atividade etc. $^{5}$

Ao conectar a produção fílmica do início do cinema ao ambiente cultural onde ela surgia, tais estudos contribuíram decisivamente para a compreensão destes filmes e de seu entorno socioeconômico. No entanto, acreditamos na necessidade de investir esforços na própria imagem do início do cinema, guardando destes estudos a ideia geral de que tal conjunto de filmes deve ser avaliado a partir de critérios intrínsecos. Para tanto, e considerando o escopo deste trabalho, tomaremos alguns filmes de Louis Lumière, avaliando-os para além de suas conexões com as imagens do final do século XIX.

Na fortuna crítica relacionada aos filmes do período, parece-nos que há um campo inexplorado, justamente quanto ao aspecto que nos parece mais evidente: a

\footnotetext{
${ }^{2}$ Consideramos a delimitação comumente aceita para o período, de 1894 (embora o marco inaugural simbólico seja a primeira projeção pública paga de filmes realizada por Louis Lumière em 28 de dezembro de 1895) até aproximadamente 1908 (COSTA, 2005, p. 34).

${ }^{3} \mathrm{O}$ que não significa que todos os historiadores e teóricos desconsiderassem ou depreciassem o período. Como o historiador Georges Sadoul, que dedicou quatro capítulos de sua História do cinema mundial ao início do cinema: I. A invenção; II. Os filmes de Lumière e de Méliès; III. A Escola de Brighton e os primórdios de Pathé; e IV. O primeiro surto norte-americano. Sua avaliação procura investir no potencial da imagem de Lumière, embora tenha as vertentes institucionalizadas do cinema como parâmetro de julgamento (SADOUL, 1983).

${ }^{4}$ Estudos de autoria de pesquisadores como Jean-Louis Comolli, Noël Burch, Tom Gunning, André Gaudreault, Charles Musser e outros, tendo a Conferência da Federação Internacional dos Arquivos de Filmes (FIAF), em Brighton, Inglaterra, em 1978, como evento aglutinador.

${ }^{5}$ A mais propagada noção que procurava reler os primeiros filmes do cinema é a de "cinema de atrações", de Tom Gunning (1994), que ressaltava no cinema do período seu caráter de exibição do inusitado e do espetaculoso, buscando causar o maravilhamento e o choque em seu público, ecoando e sendo partícipe do universo dos espetáculos de divertimento do final do século XIX, como os vaudevilles.
} 
ligação entre estes filmes e o mundo material ou, mais precisamente, o caráter transicional destas imagens, pontes entre a matéria e o cinema nascente. É este o objetivo deste artigo: promover uma leitura materialista de alguns dos primeiros filmes de Lumière, tomando-os pelo que são primordialmente, imagens, procurando neles a potência material que os formou. Recorreremos a dois autores que não costumam embasar estudos sobre os primeiros filmes do cinema. O primeiro é o filósofo Henri Bergson, considerando-se principalmente (mas não apenas) suas proposições materialistas contidas no primeiro capítulo de Matéria e memória (1990). E o também filósofo Gilles Deleuze, do qual tomaremos alguns conceitos oriundos dos livros a respeito do cinema, A imagem-movimento (1990) e A imagem-tempo (1985).

Uma advertência sobre a relação entre Bergson e o cinema: Ao enunciar sua primeira tese sobre o movimento em A evolução criadora (2005), distinguindo o movimento do espaço percorrido, Bergson usa a expressão "ilusão cinematográfica” para referir-se ao "movimento" impessoal e uniforme resultante da tentativa de se reconstituir o movimento por posições no espaço e instantes no tempo (no caso, a partir dos fotogramas). Esta reconstrução do movimento não passaria de uma tentativa fadada ao fracasso, por isso Bergson condena o cinema, por entender que perfazia a mesma coisa que a percepção natural, falseando o movimento, oferecendo cortes imóveis onde o movimento seria acrescido 6 . "Não fazemos realmente nada além de acionar uma espécie de cinematógrafo interior. (...) o mecanismo de nosso conhecimento usual é de natureza cinematográfica” (BERGSON, 2005, p. 331). Didi-Huberman (2004) defende que a crítica de Bergson seria endereçada não exatamente ao cinema, que dava seus primeiros passos no início do século XX, mas especificamente às experiências de decomposição do movimento de Étienne-Jules Marey ainda no final do século XIX. De todo modo, Bergson nunca expressou simpatia pelos filmes, é Deleuze quem faz a ligação entre o filósofo e o cinema.

Mas os filmes do início do cinema não fazem parte da classificação proposta por Gilles Deleuze para as imagens cinematográficas, agrupadas em dois grandes blocos: imagem-movimento e imagem-tempo. O período é definido como um estágio balbuciante da imagem cinematográfica, anterior ao cinema propriamente dito, "no qual a imagem está em movimento em vez de ser imagem-movimento" (DELEUZE, 1985, p. 38), vindo a tornar-se imagem-movimento (com imagens-percepções, imagens-afecções e imagens-ações plenamente constituídas), segundo De-

\footnotetext{
"Bergson critica o mesmo "erro" de afastar-se do movimento (neste caso, negá-lo) em Zenão de Eléia, autor dos mais conhecidos paradoxos de movimento e cuja fórmula geral ele mesmo enuncia: "o móvel nem no espaço em que está se move, nem naquele em que não está.” (ZENÃO, 2000, p. 143, apud Diógenes Laércio).
} 
leuze, apenas com o advento da montagem e a liberação do movimento no plano? Mas, o que seria uma "imagem em movimento"?

Bergson descobre os cortes móveis (movimentos) da duração concreta que remetem a um "todo" pela abertura (temporal) que comunica ao universo material. Para Bergson, matéria é imagem (tanto quanto é luz e é movimento). Como dito no Prefácio da sétima edição de Matéria e memória, matéria "é um conjunto de 'imagens” (1990, p. 1), sendo “imagem” não uma representação da coisa, mas a própria coisa. Por isso, dizer "imagem-movimento" é designar toda a extensão de um plano de imanência material (blocos de espaço-tempo), não havendo, por conseguinte, "imagens em movimento" enquanto estado ou estágio inferior da matéria.

É importante ressaltar que o plano de imanência não é a extensão material em si, por isso não está dado a priori para o pensamento, ao contrário, trata-se de um constructo. Cabe diferenciar, então, um plano de imanência que redesenhe as linhas do universo material, como faz Bergson no primeiro capítulo de Matéria e memória, da própria extensão concreta da matéria no universo. Bergson edifica seu plano de imanência percorrendo traço a traço o regime de todas as imagens, o regime de variação universal da matéria (universo maquínico onde cada ponto do universo material varia em relação a todos os outros pontos), mas como um constructo que não se confunde com o caos da matéria (DELEUZE, 1992, p. 182), já que o plano de imanência "não pode cobrir ou superpor-se ao caos (mesmo se se afirma que seu horizonte é infinito)” (PRADO JR., 2000, p. 314).

Deleuze recorre ao plano de imanência traçado por Bergson no primeiro capítulo de Matéria e memória para ali encontrar o que Bergson não encontrou: o surgimento do cinema enquanto extensão do plano de imanência da matéria. A questão de Bergson era a do surgimento da vida, definida como uma tela opaca que revela a luz, ou, de outra forma, como um "intervalo" no movimento incessante do regime de variação universal da matéria. Trata-se de uma mudança fundamental na matéria, de um novo regime de imagens: em meio a movimentos ininterruptos (percepção objetiva), um intervalo de movimento surge, criando na matéria um hiato temporal, tornando-a viva, gerando ali um núcleo afectivo que faz desta matéria-viva tanto uma usina de percepções subjetivas, quanto um centro de indeterminação de movimentos, de ações. Percepção, afecção e ação: para Bergson, os três aspectos fundamentais do vivo e que compõem seu circuito sensório-motor; para Deleuze, aspectos que se estenderiam ao cinema, ou, mais especificamente, ao cinema sensório-motor da

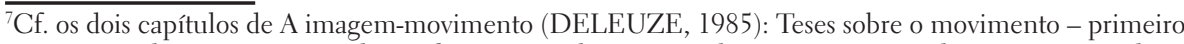
comentário de Bergson e Quadro e plano, enquadramento e decupagem (início da terceira parte deste capítulo, a partir da p. 37). 
imagem-movimento, já que para Deleuze o cinema surgiria, tal como o vivo, de um intervalo de movimento. Com a diferença que, no cinema, o agenciamento entre as imagens percepção (identificadas em um filme nos planos abertos), afecção (planos fechados como o close, o rosto) e ação (planos de tamanho médio), ao contrário do vivo, precisaria ser alvo de um processo de manipulação consciente e exterior: a montagem.

Nosso problema está em como lidar com tais imagens materiais surgidas de um intervalo de movimento (isto é, os filmes do início do cinema) que, segundo Deleuze, não são imagens-movimento, mas apenas “imagens em movimento". Na verdade, a simples menção a uma instância da matéria que não seja imagem-movimento força-nos a buscar seu estatuto material para além de uma anomalia no sistema de imagens. Acreditamos encontrar tal estatuto no que chamamos de “imagem-perceptual”. E mesmo que o foco esteja na relação dos filmes de Lumière com a matéria, perguntamo-nos se não encontraríamos neles esboços de percepções, afecções e ações, mesmo que sejam anteriores ao aparecimento da montagem.

\section{Cinema da imagem-movimento, cinema da imagem-tempo}

Partamos das relações entre o "atual” e o "virtual” que surgem explícita ou implicitamente em diversos momentos do pensamento deleuziano (cf. ALLIEZ, 1996; LÉVY, 1996; ZOURABICHVILI, 2004). O atual é o imediato, o que se presentifica em objetos concretos. Mas “do ser do sensível ao sensível ele-mesmo, do visível à sua condição, se é reconduzido a um virtual que não é menos real que o atual" (MARTIN, 2005, p. 60 - tradução nossa) ${ }^{8}$. Na verdade, aquilo que ocupa o presente só existe em sua atualidade porque uma nuvem de virtuais o acompanha, sendo a virtualidade tão "real" quanto o atual, com a diferença de que a existência do virtual não se dá em ato, mas em potência9. E, justamente, é no processo de atualização que os virtuais se atualizam num fluxo interminável, pois direções (virtuais) não anunciadas e sempre renováveis rodeiam o atual. “Todo atual rodeia-se de círculos sempre renovados de virtualidades, cada um deles emitindo um outro, e todos rodeando e reagindo sobre o atual" (DELEUZE, 1996, p. 49). São os processos de atualização que arremessam o atual para o futuro, ou, ao contrário, trazem de volta o passado, atualizando-o como lembrança. Um processo de diferenciação se constitui

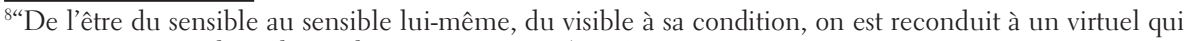
n’est pas moins réel que l'actuel.” (MARTIN, 2005, p. 60).

"Virtual: do latim “virtus", que derivou "virtualis”: força, potência (LALANDE, 1999).
} 
entre o virtual e o atual: o fluxo de multiplicidade virtual precipita-se em direção à multiplicidade atual, à singularidade.

As relações entre o atual e o virtual são importantes fios condutores da classificação deleuziana do cinema em imagem-movimento e imagem-tempo. Tal repartição, repleta de passagens, ressoa o projeto maior de Deleuze de crítica à representação ${ }^{10}$. O cinema da imagem-movimento, identificado, grosso modo, ao cinema clássico, se constituiria pela representação de um tempo cronológico, tendo como correlato o movimento normalizado em raccords racionais que garantem a fluência e a não ruptura do conjunto. Tal realidade totalizante pressupõe a independência dos objetos e dos meios, propiciando o surgimento de um cinema de ação no qual a narração dita orgânica (onde cada elemento contribui para um objetivo) aspira à "verdade" e à apartação entre o bem e o mal (DELEUZE, 1985).

Este cinema teria tido seu apogeu antes da Segunda Grande Guerra. O impacto causado pela apropriação da imagem-movimento por regimes e sistemas político-econômicos que a usaram como "portadora da verdade"11 (entre outros motivos) (DELEUZE, 1985, p. 252-264), fez com que potências próprias da imagem cinematográfica, que haviam despontado anteriormente em obras isoladas ${ }^{12}$, viessem finalmente à tona. A primeira reação coletiva foi levada a cabo pelo Neorrealismo italiano ainda durante o conflito mundial, desdobrando-se em novos caminhos no pós-guerra. Nesses filmes surgem os primeiros sinais de falência dos esquemas sensório-motores da imagem-movimento, uma crise generalizada da ação que afetava o cinema e que propiciaria, segundo Deleuze, a emergência das imagens óticas e sonoras puras (isto é, imagens-percepção e imagens-afecção desconectadas de seus prolongamentos ativos, da ação) $)^{13}$ (DELEUZE, 1990, p. 9-36) em filmes de perambulação, com ligações frágeis entre os personagens imersos em situações dispersas (BAZIN, 1991).

A emergência das imagens óticas e sonoras puras abriu espaço para uma

\footnotetext{
${ }^{10} \mathrm{Em}$ Diferença e repetição (1988), Deleuze faz sua crítica (de inspiração nietzschiana) mais contundente à "representação". Respondendo a Nietzsche, que denunciava a história da filosofia em um dos capítulos de Crepúsculo dos ídolos como "a história de um erro" ("como o 'mundo verdadeiro' se tornou finalmente fábula") (NIETZSCHE, 2006, p. 31), Deleuze escreve que "a história do longo erro é a história da representação" (Deleuze, 1988, p. 471).

${ }^{11}$ Da inclinação propagandística dos filmes de ação de Hollywood e do cinema soviético à apropriação da UFA e de todo o sistema de produção de cinema na Alemanha pelo nazi-fascismo europeu, cujo exemplo maior é Triunph des willens (O triunfo da vontade, 1935), de Leni Riefenstahl.

${ }^{12}$ Como Yasujiro Ozu e Orson Welles.

${ }^{13}$ Deleuze fornece exemplos interessantes deste novo cinema de personagens que veem e que compreendem o que se passa, mas que já não são mais capazes de agir: da heroína de Stromboli (1950), de Roberto Rossellini, ao fotógrafo com a perna quebrada e que testemunha um crime em Rear window (Janela indiscreta, 1954), de Alfred Hitchcock. Mas foi Ozu o criador das imagens óticas e sonoras puras ainda antes da Segunda Guerra (DELEUZE, 1990, p. 23-28).
} 
conversão completa das imagens cinematográficas e uma imagem de natureza diversa surgia com o cinema moderno: a imagem-tempo. Aparecem no cinema, com a imagem-tempo, as imagens não-representacionais nas quais o tempo se apresenta diretamente e não mais mediado pelo movimento normatizado da ação, dos filmes de ação: à memória psicológica do flashback, entram em cena as indefinições temporais, as memórias de mundo, os mergulhos em temporalidades desmesuradas ${ }^{14}$, em universos fílmicos onde a anomalia de movimento (falso-raccord) é a tônica. As descrições (óticas e sonoras) repõem constantemente os objetos e os meios, fazendo com que a narração torne-se falsificante (F for fake [Verdades e mentiras], 1973, de Orson Welles) (DELEUZE, 1990).

A diferença entre imagem-movimento e imagem-tempo torna-se nítida ao opormos aquela ao primeiro aspecto da imagem-tempo: a imagem-cristal. A imagem-movimento se apoia em constantes processos de atualização de virtuais. É o caso, por exemplo, de como o passado (virtual) surge em um filme clássico, como flashback, isto é, como "antigo presente", lembrança psicológica presentificada (alguém lembra...). Atualizado, o virtual deixa de ser potencialidade, torna-se atual na imagem-movimento, operando segundo parâmetros de utilidade: uma lembrança é evocada pela testemunha de um crime e, assim, o assassino poderá ser descoberto. Algo de natureza completamente diferente acontece na maneira como a virtualidade se apresenta na imagem-cristal. Os virtuais já não mais se atualizam, mas cristalizam-se com atuais, isto é, compõem uma imagem bifacial onde há coalescência entre o objeto real (atual) e sua imagem especular imediata (virtual) - a sequência dos espelhos em The lady from Shangai (A dama de Shangai, 1948, de Orson Welles). O circuito pode aumentar, ir além do objeto real e seu virtual imediato, abarcar o infinito, mas a bifacialidade coalescente da imagem-cristal se manterá. E mesmo havendo diferença de natureza entre o atual e o virtual, entre presente e passado, mesmo que sejam distintos, na imagem-cristal estão em relações de indiscernibilidade (já que o tempo surge diretamente na imagem e não mais representado em passado ou presente como na imagem-movimento), além de trocarem constantemente de papel: afinal, onde está o passado e onde está o presente, como separar a opacidade da transparência da imagem, o que é atual e o que é virtual em L’année dernière à Marienbad (Ano passado em Marienbad, 1961, de Alain Resnais)? Na imagem-cristal o passado não é evocado, o passado apresenta-se, dá-se a ver (DELEUZE, 1990, p. 87-120) ${ }^{15}$.

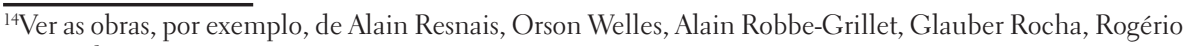
Sganzerla etc.

${ }^{15}$ Encontramos a argumentação sobre a imagem-cristal no capítulo Os cristais de tempo, em A imagemtempo. Deleuze trabalha como exemplos privilegiados de imagem-cristal, aspectos contidos nas obras de
} 
Cinema hipermaterialista: Bergson, Deleuze e a virtualização da matéria nos filmes de Louis Lumière

| Marcelo Carvalho

\section{Filmes de Lumière}

Além do apuro dos enquadramentos "impressionistas", é perceptível em muitos dos filmes realizados por (ou atribuídos a) Louis Lumière um empenho em exibir pequenas ações e gestos esboçados, quando não gags como L'arroseur arrosé (1895), Les joueurs de cartes arrosés (1896) e Bonne d'enfants et soldat (1897). Seguia uma tendência que vinha de Thomas Alva Edison e William Dickson, inventores do cinetoscópio e idealizadores de curtos trechos fílmicos cujo conteúdo exibia pequenos atos filmados no estúdio Black Maria (SADOUL, 1983). Sigamos, contudo, outros filmes creditados à Lumière, onde, inversamente, as relações materiais perceptivas suplantam as pequenas ações e os gestos apenas esboçados ou que, pela repetição ou desfile quase mecânico dos móveis de todo tipo, pessoas, veículos etc., a paisagem material se impõe como um elemento evidente ${ }^{16}$.

Em primeiro lugar, Place des Cordeliers à Lyon (1895). Este não é o único filme de Lumière onde a câmera documenta uma rua de cidade. A câmera fixa mostra uma esquina movimentada da cidade de Lyon. Ao fundo e ao centro do quadro, uma fileira de fachadas de prédios de apartamentos filmados em perspectiva (enquadramento ao gosto de Lumière) com amplas janelas, mansardas, toldos de lojas de rua etc. Também ao fundo, bem à esquerda, em perspectiva frontal, mais um prédio de apartamentos. A arquitetura e o equipamento urbano de Lyon servem de cenário imóvel para o vai vem de transeuntes que cruzam o quadro ao fundo e em segundo plano. Próximos à câmera posicionada acima do ponto de vista médio dos olhos de uma pessoa, vemos em certo ponto do filme a sombra da cabeça de uma mulher portando um chapéu feminino e segurando um guarda-chuva, uma cabeça sem rosto, quase um vulto, um puro movimento como o que pode ser visto um pouco antes, quando um homem passa pelo mesmo lugar em frente à câmera. Na larga avenida, transeuntes seguem apressados e carruagens puxadas por cavalos carregam pessoas e cargas, num desfile coletivo, atual e anônimo cujo destino e origem jamais saberemos.

\footnotetext{
Max Ophuls, Jean Renoir, Federico Fellini e Luchino Visconti, justamente, as dubiedades da imagem num jogo de indiscernimento entre o atual e o virtual. Como na questão sempre reposta por Fellini: espetáculo ou vida? Mas os processos de cristalização podem ser achados em inúmeros exemplos, justamente pela centralidade da imagem-cristal dentro do sistema da imagem-tempo.

${ }^{16}$ Ao longo do texto são citados vários filmes de Louis Lumière. Para um acesso rápido aos cinco filmes de Lumière sobre os quais basearemos mais fortemente nossa argumentação, sugerimos a reunião de seus filmes em: <https://www.youtube.com/watch?v=9Ub2AJQipm4>, onde são encontrados Récréation à la matière (em 9m16s), Champs-Elysée (em 21m39s) e Baignade en mer (em 25m55s). Para o filme La sortie de l'usine Lumière à Lyon, acessar (em 19m20s) <https://www.youtube.com/watch?v=oOqeWNK5sDw>. E para o filme Place des Cordeliers à Lyon, acessar $<$ https://www.youtube.com/watch?v=gbVxHZqumc8>. Links acessados em 26 de fevereiro de 2016.
} 
Este é o quadro que retemos de Place des Cordeliers à Lyon: um movimento geral sobre um fundo imóvel de prédios, uma massa móvel onde aqui e ali se divisam pessoas, veículos e animais. E se usamos termos e expressões como "vulto" e "massa móvel”, não é em referência a uma pretensa falta de qualidade do filme original ou a alguma precariedade na tecnologia do cinematógrafo, pelo contrário. $\mathrm{O}$ aparelho desenvolvido por Lumière notabilizou-se pela qualidade das imagens obtidas em comparação ao que conseguiram os inventos anteriores. Mas é que, mesmo que tenha projetado imagens bem definidas no dia de sua primeira exibição, mesmo que seja nítido tratar-se de alguns segundos prosaicos e aleatórios de uma avenida de Lyon do final do século XIX, o equipamento (a câmera-projetor Lumière) colocado naquele local registrou o movimento decorrente do ordenamento urbano quase como se registram hoje os fremidos dos átomos - e cada vez temos imagens mais nítidas do universo microscópico. O filme está apenas um passo adiante da objetividade da matéria que percebe por todos os seus pontos, como na conhecida fórmula de Bergson ${ }^{17}$. Evidentemente, vemos ações ali, pessoas efetivamente caminham e conduzem carruagens, mas são relações sensório-motoras bem incipientes, casuais e não-necessárias, flashes de um pequeno trecho espaço-temporal do cotidiano da cidade de Lyon onde os movimentos das pessoas exibidos na tela valem por si e não pelas relações perceptivas, afectivas e ativas que efetivamente as animavam naquele distante dia de 1895.

Ao contrário de filmes posados como Le repas de bébé (1895), filmes como Place des Cordeliers à Lyon (ou Champs-Elysées, de 1896, onde vemos a avenida parisiense repleta de transeuntes e carruagens puxadas por cavalos) ${ }^{18}$, ao registrarem o espírito de urbanicidade da "vida moderna" do final do século XIX, notabilizam-se pelo movimento diversificado de diferentes vetores tomados em bloco num conjunto (quadro) perceptivo que, mais do que móvel, apresenta-se convulso, mesmo se os elementos imóveis venham a dominar o quadro, ou mesmo que cada móvel esteja nítido e plenamente identificável. Essa convulsão no quadro surge também em cenas filmadas em ambientes mais controlados, como é o caso de Récréation à la matière (1895) onde tal estado de movimentação ininterrupta é ainda mais evidente. O quadro nesse filme se divide em duas partes segundo uma separação horizontal: acima as colunas e os três arcos plenos da escola sob os quais há um corredor escuro; abaixo e

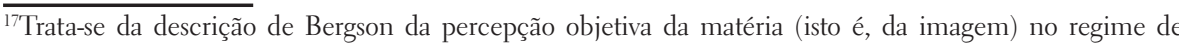
variação universal (universo material), onde "todas as imagens agem e reagem umas sobre as outras em todas as suas partes elementares segundo leis constantes, que chamo leis da natureza.” (BERGSON, 1990, p. 9).

${ }^{18}$ Há também o filme Champs-Elysées (voitures) (1896) onde já aparecem, em meio aos transeuntes e às charretes puxadas a cavalo, um veículo motorizado e um bonde.
} 
à frente, tomando toda a parte inferior do quadro, os alunos movimentam-se, entram e saem do quadro, como pequenos pedaços da matéria-movimento que não cessam de convulsionarem-se.

Com Place des Cordeliers à Lyon e Récréation à la matière não estamos mais no regime da variação universal, mas ainda o divisamos num momento logo após a instituição do intervalo de movimento que criou o cinema. Encontramos algo similar em outro filme de Lumière, dessa vez uma quase gag, Baignade en mer (1895). Em vez da cidade na qual um fundo de fachada garante uma placa fixa onde os móveis transitam, como em Place des Cordeliers à Lyon, encontramo-nos num ambiente marinho: à beira-mar, alguns banhistas perfazem um percurso circulatório, primeiro correndo sobre um pequeno píer de madeira, pulando no mar no final do píer, nadando de volta até uma rocha entre o mar e a praia e, fora do quadro, ganhando novamente o píer para executar a mesma série de movimentos. Quase todo o quadro é ocupado pelas ondas do mar, matéria fluente que se sobrepõe a si mesma pelo movimento ritmado do ir e vir das ondas. Mais ainda do que em Place des Cordeliers à Lyon, onde os habitantes da cidade são quase espectrais, vultos humanos atravessando o espaço, em Baignade en mer o movimento repetitivo dos banhistas responde a um universo perceptivo como resultante de um movimento mecânico, integrado - embora tendo caráter bem diferente - ao movimento das ondas do mar. Estão em jogo dois vetores contrastantes enquanto blocos de movimento: as linhas contínuas do avanço das ondas e os seres que entram e saem do mar num circuito fechado duas inscrições do mundo material que se interpenetram.

La sortie de l'usine Lumière à Lyon (1894) é considerado o primeiro filme realizado por Louis Lumière (salvo os experimentos em laboratório). Há três versões conhecidas, realizadas em diferentes momentos do ano. Veem-se nas três versões desse filme - com enquadramentos quase idênticos - dois portões, um pequeno e outro maior. Ao fundo da imagem encontra-se o interior de um galpão e o madeirame do telhado. Trata-se de um local de trabalho, dado o movimento geral de dispersão de trabalhadores ao final do expediente - tema explícito do filme. Apesar de semelhantes, cada versão tem suas particularidades quanto aos móveis em atuação: há trabalhadores sobre bicicletas, além de cachorros que transitam entre os trabalhadores e cavalos puxando uma carroça (mais exatamente, numa versão há dois cavalos, noutra há um e na terceira, nenhum). Uma das três filmagens teria sido realizada logo após o cinematógrafo ter sido dado como pronto, talvez ainda em meados de 1894, sendo esta a primeira filmagem realizada no exterior. Outra versão foi realizada para ser a primeira filmagem oficial a ser apresentada na primeira projeção pública paga de 
cinema. Nesta versão há um cachorro, bicicletas e nenhum cavalo ${ }^{19}$.

Nas três versões desse filme o eixo da câmera está em um ângulo de $90^{\circ}$ com relação ao fundo numa perspectiva frontal. Seja o galpão um depósito, fábrica ou estabelecimento comercial, este não é um espaço determinado, com coordenadas estabelecidas como numa imagem-ação. Ao saírem do galpão, os trabalhadores dirigem-se para a direita e para a esquerda, ultrapassando os limites do quadro e alguns, inclusive, encaminham-se em direção à câmera, saindo do quadro próximo a ela. O movimento dos trabalhadores denuncia o espaço que existe para além do recorte mostrado pelo enquadramento, não exatamente um espaço-fora-da-tela, característica que viria a se tornar um elemento fundamental da imagem cinematográfica (BURCH, 1992), mas um "espaço fora do quadro". Como em Place des Cordeliers à Lyon há um cenário imóvel ao fundo sobre o qual há elementos móveis de natureza diversa, movimento geral convulso surgido do meio do quadro e saindo pelas bordas. Também aqui não restam dúvidas quanto aos móveis em quadro, são pessoas, carroças, bicicletas e animais em ações esboçadas que compõem um fragmento da rotina de trabalho sobre a qual sabemos apenas que, em determinada hora do dia, há um fluxo intenso e coordenado de pessoas do interior do galpão para a rua em frente.

Não são os indícios de esquemas sensório-motores em formação que estão em jogo em La sortie de l'usine Lumière à Lyon, mas o movimento em conjunto de uma massa heterogênea presente em quaisquer dos três filmes, cujos conteúdos específicos são irrelevantes. Nada sabemos sobre o que está ao redor do espaço filmado, nem para onde vão os trabalhadores que saem do local de trabalho que poderia, afinal, ser em qualquer lugar. O espaço filmado está desconectado de quaisquer determinações geográficas que nos insiram numa realidade dada (embora saibamos, por adição exterior ao próprio filme e a posteriori, que se trata da fábrica da família Lumière na cidade de Lyon). Vemos, enfim, um espaço qualquer, da mesma forma que a avenida movimentada de Place des Cordeliers à Lyon e a beira-mar de Baignade en mer.

\footnotetext{
${ }^{19} \mathrm{O}$ Institut Lumière e a Association Frères Lumière, em parceria com os Archives du Film du Centre National de la Cinématographie, promoveram a restauração dos filmes Lumière no âmbito das comemorações do centenário da primeira projeção pública paga do cinema. Um dos produtos desse trabalho foi a reunião dos filmes Lumière realizados entre 1895 e 1897 chamada The Lumière Brothers' First Films. A narração e os comentários em off são do cineasta Bertrand Tavernier que, entre outros filmes dos pioneiros do cinema, comenta as três versões de La sortie de l'usine Lumière à Lyon, bem como os motivos pelos quais foram realizadas. Este filme pode ser acessado em <https:/www.youtube.com/ watch?v=vuG56syRl9k $>$. Link acessado em 22 de maio de 2016.
} 
Cinema hipermaterialista: Bergson, Deleuze e a virtualização da matéria nos filmes de Louis Lumière

| Marcelo Carvalho

\title{
A memória mais restrita: o circuito A-O
}

As imagens desses filmes exibem-se sobre um plano de imanência que se caracteriza por uma forte inscrição espacial, espaço tributário do regime de variação universal onde volumes se movem, se entrecruzam, se superpõem. Não são imagens análogas ao que "representariam", mas extensões imanentes sobre um campo transcendental (plano de imanência) onde se encontram o que André Parente chama de imagens-matéria, “acontecimentos que antecedem o homem e sua relação sensório-motora com o mundo. São as próprias coisas, as coisas em si” (PARENTE, 2000, p. 14). Se comparado às experiências visuais anteriores, como a pintura e a fotografia, o cinematógrafo Lumière traz como novidade ser uma progressão interna, uma sucessão imanente que define não apenas o modo como suas imagens são vistas, mas, principalmente, como tais imagens se constituem, isto é, em quais condições elas se fazem cinema:

\begin{abstract}
A forma de ver na pintura, e mais tarde na fotografia, é completamente dependente de um tempo de contemplação que é materialmente irrestrito. Os filmes de Lumière, entretanto, aparecem e desaparecem, e, tendo por base este movimento, cada um dos fotogramas aparece e desaparece, imperceptivelmente. Concomitantemente, o espectador é pego por este movimento, dominado por suas forças (DECORDOVA, 1990, p. 77 - tradução nossa) $)^{20}$.
\end{abstract}

No entanto, Decordova considera o cinema de Lumière cotejando-o a um "modo de representação", questionando-se sobre a relação entre o cinematógrafo Lumière e o discurso imagético oriundo do Renascimento, como o aparecimento e o desaparecimento "em perspectiva" dos trabalhadores em La sortie de l'usine Lumière à Lyon. Ou ainda, ao analisar Démolition d'un mur (1895) como sendo "um espetáculo completamente dependente do efeito de movimento oriundo do sistema de perspectiva da Renascença” (DECORDOVA, 1990, p. 81 - tradução nossa) ${ }^{21}$. Para o autor, não haveria como Lumière subtrair-se ao discurso da tradição, já que "as questões de composição e decomposição são trocadas pelo problema do quadro" (DECORDOVA, 1990, p. 79 - tradução nossa) 22. Não há porque desconsiderar tal filia-

\footnotetext{
20"The play of vision in painting, and later photography, had been fully contingent upon a materially unrestricted time of contemplation. The Lumière films, however, appear and disappear, and, at the base of this movement, each 'photogram' appears and disappears, imperceptibly. Left out in this movement, the spectator is at the same time taken up by it, subjected to its force.” (DECORDOVA, 1990, p. 77).

${ }^{21}$ "It is a spectacle entirely dependent upon the effect movement had on the system of Renaissance perspective." (DECORDOVA, 1990, p. 81).

${ }^{22}$ "The problems of composition and discomposition are shifted on to the problem of the frame."
} 
ção. No entanto, insistimos em investigar de que forma a matéria, o mundo material da percepção objetiva imiscui-se nesses filmes. Perguntamo-nos sobre o momento de constituição da imagem-movimento no cinema, nos filmes de Lumière, momento este onde o circuito sensório-motor ainda não se mostrava plenamente constituído.

Sabemos quão intensa é a sensação nesses filmes de um "presente irredutível", de uma temporalidade que não teria passado nem futuro, memória ou projeção, apenas a imagem atual de trabalhadores saindo de seu local de trabalho, vultos mais ou menos definidos a caminhar pelas ruas, banhistas numa brincadeira repetitiva que nos sugere um loop interminável que pareceria agrilhoar a passagem do tempo. Quase como se esses filmes expressassem nada além de um instante captado pela câmera.

A questão do "instante" esteve presente enquanto uma importante categoria definidora da "modernidade" no século XIX ${ }^{23}$. Mas se o instante é um dado do cinema enquanto unidade técnica constituidora do mecanismo de captação e projeção de vistas fixas e equidistantes dos objetos em frente à objetiva da câmera, já não é enquanto dado da imagem cinematográfica, pois, em condições de existência previstas no cinema, não estamos diante de instantes imóveis, mas de cortes móveis da duração, o movimento per si. O instante enquanto presentificação inamovível é burlado pelo cinema, cujo plano de imanência perfaz um continuum de movimento perceptivo contíguo ao plano da matéria. O presente fixo só existiria, enfim, como uma abstração artificial, destituído de seu caráter de passagem. No cinema, "esse presente já está, ao mesmo tempo, sempre indo embora.” (CHARNEY, 2004, p. 324).

Por seu turno, Bergson (1990) diz-nos que não existe (na imagem sensório-motora que somos) percepção pura e instantânea que absorvesse por completo o intervalo. A memória se intromete na percepção, havendo na percepção subjetiva, mesmo a mais imediata e simples, a incursão de lembranças em graus variados. Enfim, não existiria imagem surgida após um intervalo de movimento, seja esta imagem matéria viva ou cinema, que fosse apenas percepção atual, já que todo atual é acompanhado por uma nuvem de virtualidade ${ }^{24}$. No entanto, Bergson deixa uma brecha. É que, pelo menos idealmente, haveria a possibilidade de existência de uma imagem

\footnotetext{
(DECORDOVA, 1990, p. 79).

23" Por meio da categoria do instante, pensadores como Walter Pater, Walter Benjamin, Martin Heidegger e Jean Epstein procuraram resgatar a possibilidade da experiência sensorial em face do caráter efêmero da modernidade. $\mathrm{O}$ conceito do instante forneceu um meio de fixar um momento de sensação, no entanto esse esforço de estabilidade teve que confrontar o fato inevitável de que nenhum instante podia permanecer fixo" (CHARNEY, 2004, p. 317 e 318).

${ }^{24}$ Já no primeiro capítulo de Matéria e memória, Bergson adverte-nos que a “percepção pura”, sem interferência das lembranças, só existe de direito, não de fato, mas que a tomará como estratégia argumentativa para diferir percepção de memória (1990).
} 
intervalar que estivesse diretamente conectada à imagem objetiva, isto é, à matéria:

A heterogeneidade qualitativa de nossas percepções sucessivas do universo deve-se ao fato de que cada uma dessas percepções estende-se, ela própria, sobre uma certa espessura de duração, ao fato de que a memória condensa aí uma multiplicidade enorme de estímulos que nos aparecem juntos, embora sucessivos. Bastaria dividir idealmente essa espessura indivisa de tempo, distinguir nela a multiplicidade ordenada de momentos, em uma palavra, eliminar toda a memória, para passar da percepção à matéria, do sujeito ao objeto (BERGSON, 1990, p. 52 e 53 - grifo nosso).

O problema é que não seria possível eliminar a memória da imagem viva que somos, passado que retorna e que reveste a percepção atual em prol do reconhecimento. Mas Bergson (1990)25 define dois tipos de reconhecimento. O primeiro é o reconhecimento automático, que opera por prolongamentos dos movimentos: a percepção de um objeto prolonga-se numa ação segundo uma economia de utilidade, desta para outra percepção etc., em relações horizontais por associações num mesmo plano. São mecanismos sensório-motores como nos animais (de um terreno ao outro onde está o alimento, deste para a árvore que dá a sombra etc.) ou em nossos hábitos. E há o reconhecimento atento, onde a percepção já não se prolonga mais em novos movimentos e minha atenção, antes dispersa e errante, retorna constantemente ao objeto, recriando-o completamente e de maneira diferente a cada vez - o mesmo objeto, vários planos.

Bergson elabora um esquema da relação entre memória e objeto determinando circuitos mnemônicos a partir do objeto (BERGSON, 1990, p. 83), chamando de $A$ a percepção subjetiva imediata e $O$, o objeto percebido. Trata-se do circuito mais restrito da memória, contendo "apenas o próprio objeto $\mathrm{O}$ e a imagem consecutiva que volta para cobri-lo.” (BERGSON, 1990, p. 84). Há uma progressão tanto em direção aos esforços da memória (camadas $B, C$ e $D$ e adiante, todas englobando a totalidade da memória a cada vez), quanto em direção ao objeto (níveis B', C' e D', de acordo com as condições de percepção do objeto). Aqui já não acionamos mais uma imagem sensório-motora por associações de objetos, mas "construímos da coisa uma imagem ótica (e sonora) pura, fazemos uma descrição." (DELEUZE, 1990, p. 60). E se considerássemos a imagem sensório-motora igualmente uma descrição, esta só poderia ser orgânica (regime orgânico da imagem-movimento), enquanto a imagem ótica e sonora remeteria necessariamente ao inorgânico (regime inorgânico da imagem-tempo).

${ }^{25}$ No capítulo dois de Matéria e memória (1990): Do reconhecimento das imagens. A memória e o cérebro. 
Um ato de atenção implica uma tal solidariedade entre espírito e seu objeto, é um circuito tão bem fechado, que não se poderia passar a estados de concentração superior sem criar circuitos completamente novos envolvendo o primeiro, e que teriam em comum apenas o objeto percebido (BERGSON, 1990 , p. 84).

O que importa é que esse "outro tipo de percepção" (DELEUZE, 1990, p. 61), a descrição ótica e sonora, desconectou-se dos movimentos habituais em prol de concentrar-se num único objeto, lugar, ponto de vista. "A situação puramente ótica e sonora (descrição) é uma imagem atual, mas que, em vez de se prolongar em movimento, encadeia-se com uma imagem virtual e forma com ela um circuito" (DELEUZE, 1990, p. 63). Assim, nessa “outra” percepção estão um atual e um virtual, que, diferindo-se em natureza, "refletem-se sem que se possa dizer qual é o primeiro, e tendem, em última análise, a se confundir caindo num mesmo ponto de indiscernibilidade." (DELEUZE, 1990, p. 61).

\section{Conclusão: a virtualização da matéria e a imagem-perceptual}

Vimos que La sortie de l'usine Lumière à Lyon, Place des Cordeliers à Lyon, Champs-Elysée, Récréation à la matière e Baignade en mer apresentam como características comuns o espaço qualquer e uma composição “perceptual”, isto é, uma organização de traços perceptivos que ainda não conformaram percepções, afecções ou ações plenas. Há nesses filmes trechos de espaço que ainda guardam marcas indeléveis do regime de variação universal da matéria, identificados pelo caráter incipiente das imagens percepção, afecção e ação. Sem um circuito sensório-motor plenamente estabelecido, são imagens óticas que valem por si, pelo que apresentam. E, justamente, "uma situação puramente ótica ou sonora se estabelece no que chamávamos de “espaço qualquer', seja desconectado, seja esvaziado." (DELEUZE, 1990, p. 14). As imagens de Lumière legariam ao cinema vindouro a tarefa de completar os prolongamentos perceptivos, afectivos e ativos típicos da imagem-movimento, constituindo-se assim o circuito sensório-motor pleno do cinema. Resta-nos saber o que desempenharia nos filmes de Lumière o papel do virtual, já que há uma tão pronunciada conexão com o "atual", e a concomitante ausência de uma memória larga.

Com esses filmes de Lumière estamos numa espécie de menor circuito A-O que, por um caráter excepcional de desconexão da lembrança pura, da dimensão temporal enquanto passado inteiro virtual, compõe uma camada imediata e recém construída onde se encontram a imagem percebida atual e o objeto virtual num plano 
de imanência da matéria. Se o sistema sensório-motor nesses filmes ainda não se constituiu plenamente, tampouco ali encontraríamos uma imagem ótica pura que correspondesse exatamente ao reconhecimento atento enquanto imagem da imagem-tempo porque as relações contidas apenas no menor circuito de uma imagem ótica pura diferem daquelas em jogo no reconhecimento atento integral. Impossibilitadas de formar novos circuitos de memória e de renovar descrições cristalinas do objeto, as imagens desses filmes mantém-se conectadas à matéria de onde partiram, num estado presente fortemente material. Aliás, este é um dos fundamentos do primeiro capítulo de Matéria e memória enquanto inclinação materialista: a supressão de toda conexão da imagem atual com sua miríade virtual, supressão que não existe de fato na matéria viva, nos orientaria imediatamente da percepção subjetiva para a matéria objetiva, para o continuum perceptivo próprio à matéria objetiva. É a situação que encontramos no cinema de Lumière, em seus filmes mais fortemente conectados ao regime de variação universal: a não constituição da memória ancora fortemente estes filmes à matéria; concomitantemente, a redução do objeto virtual e de sua imagem atual ao menor circuito os conduz necessariamente a uma coalescência material.

Chamemos estas imagens não de "imagens em movimento", mas de “imagens-perceptuais" por envolverem um constructo perceptivo, um fluxo perceptivo subjetivo em construção (pois ainda não completamente prolongado em afecções e ações), e por encontrarem-se ainda próximos do regime da variação universal, do universo material. Mesmo que haja coalescência e distinção entre a imagem cinematográfica atual e a matéria virtualizada (em um plano de imanência enquanto recomposição virtual dos traços da matéria objetiva), esta não pode ser confundida com uma imagem-cristal da imagem-tempo, diferindo-se dela por apresentar a imagem atual e o objeto virtual circunscritos no menor circuito de reconhecimento (A-O) como imagens discerníveis e sem que venham a trocar suas funções. Se o cinema da imagem-movimento apresenta esquemas sensório-motores plenamente estabelecidos em atualizações (presentificações) de virtualidades, a presença de um esquema sensório-motor ainda por se desenvolver faz das imagens de La sortie de l'usine Lumière à Lyon, Place des Cordeliers à Lyon, Champs-Elysée, Récréation à la matière e Baignade en mer imagens óticas atuais que virtualizam a matéria (seu plano de imanência) ao apresentar dela uma modulação, uma extensão tornada cinema no mais estreito circuito onde a matéria se rebate nas imagens cinematográficas.

A imagem-perceptual em Lumière é uma imagem ótica não por desconexão do sistema sensório-motor, tal como ocorreu com a irrupção do Neorrealismo e 
consequente surgimento da imagem-tempo, mas, ao contrário, por apresentar um esquema sensório-motor incipiente, ainda em construção. Sem reconhecimentos, sejam habituais ou atentos, o tempo nesses filmes é o reflexo da progressão dos movimentos, da matéria virtualizada que ocupa o lugar da "memória” no menor circuito, da matéria como um plano de imanência (sempre virtual) que insiste sob a atualidade das imagens dos filmes, daí a forte conexão da imagem-perceptual com o atual, com o presente. Enfim, o pleno desenvolvimento dos impulsos perceptivos, afectivos e ativos em imagem-percepção, imagem-afecção e imagem-ação (circuito sensório-motor) ensejará não apenas o aparecimento da narração no cinema (a partir da montagem), como fará da imagem-movimento uma imagem representacional. Em contraponto, a imagem-perceptual continuará sendo uma instância não-representacional de onde se manifesta a imagem-movimento do cinema.

\section{Referências bibliográficas}

ALLIEZ, É. Deleuze filosofia virtual. Rio de Janeiro: Editora 34, 1996.

BAZIN, A. O cinema - ensaios. São Paulo: Brasiliense, 1991.

BERGSON, H. A evolução criadora. São Paulo: Martins Fontes, 2005.

Matéria e memória. São Paulo: Martins Fontes, 1990.

BURCH, N. Práxis do cinema. São Paulo: Perspectiva, 1992.

CHARNEY, L. "Num instante: o cinema e a filosofia da modernidade". In. CHARNEY, L.; SCHWARTZ, V. R. (orgs.). O cinema e a invenção da vida moderna. São Paulo: Cosac Naify, 2004.

COSTA, F. C. O primeiro cinema - espetáculo, narração, domesticação. Rio de Janeiro: Azougue, 2005.

DECORDOVA, R. "From Lumière to Pathé: The break-up of perspectival space". In: ELSAESSER, T.; BARKER, A. (orgs.). Early cinema: space - frame - narrative. London: British Film Institute, 2013.

DELEUZE, G. A imagem-movimento. São Paulo: Brasiliense, 1985.

. A imagem-tempo. São Paulo: Brasiliense, 1990.

Diferença e repetição. Rio de Janeiro: Graal, 1988.

"O atual e o virtual". In: ALLIEZ, Eric. Deleuze filosofia virtual. Rio de Janeiro: Editora 34, 1996.

DELEUZE, G.; GUATTARI, F. O que é a filosofia? Rio de Janeiro: Editora 34, 1992. 
DIDI-HUBERMAN. G. "La durée de toute chose". In: DIDI-HUBERMAN, G.; MANNONI, L. Mouvements de l'air - Étienne-Jules Marey, photographe des fluides. Paris: Gallimard / Réunion des Musées Nationaux, 2004.

GUNNING, T. "A grande novidade do cinema das origens: Tom Gunning explica suas teorias a Ismail Xavier, Roberto Moreira e Fernão Ramos". Revista Imagens, Campinas, n² 2, agosto 1994.

LALANDE, A. Vocabulário técnico e crítico da filosofia. São Paulo: Martins Fontes, 1999.

LÉVY, P. O que é o virtual? São Paulo: Editora 34, 1996.

MACHADO, R. Deleuze, a arte e a filosofia. Rio de Janeiro: Jorge Zahar, 2009.

MARTIN, J.-C. La philosophie de Gilles Deleuze. Paris: Éditions Payot \& Rivages, 2005.

NIETZSCHE, F. Crepúsculo dos ídolos - ou como filosofar com o martelo. São Paulo: Companhia das Letras, 2006.

PARENTE, A. Narrativa e modernidade - os cinemas não-narrativos do pós-guerra. Campinas: Papirus, 2000.

PRADO JR., B. "A ideia de plano de imanência”. In: ALLIEZ, É. Gilles Deleuze: uma vida filosófica. São Paulo: Editora 34, 2000.

SADOUL, G. História do cinema mundial (vol. I). Lisboa: Horizonte, 1983.

ZENÃO DE ELÉIA. Os pensadores (v. Pré-socráticos). São Paulo: Nova Cultural, 2000.

ZOURABICHVILI, F. Deleuze, una filosofia del acontecimiento. Buenos Aires: Amorrortu, 2004.

\section{Referências Audiovisuais}

BAIGNADE en mer. Louis Lumière, França, 1895.

BONNE d'enfants et soldat. Louis Lumière, França, 1897.

CHAMPS-Elysées. Louis Lumière, França, 1896.

DEMOLITION d'un mur. Louis Lumière, França, 1895.

L'ARROSEUR arrosé. Louis Lumière, França, 1895.

LA SORTIE de l'usine Lumière à Lyon. Louis Lumière, França, 1894.

LES JOUEURS de cartes arrosés. Louis Lumière, França, 1896.

PLACE des Cordeliers à Lyon. Louis Lumière, França, 1895.

RECRÉATION à la matière. Louis Lumière, França, 1895.

submetido em: 29 fev. 2016 | aprovado em: 07 maio 2016. 